\title{
EROSÃO ENTRE SULCOS EM DIFERENTES CONDIÇÕES DE COBERTURA DO SOLO, SOB CULTIVO DA CANA-DE-AÇÚCAR ${ }^{(1)}$
}

\author{
Sandro Augusto Bezerra ${ }^{(2)} \&$ José Ramon Barros Cantalice ${ }^{(3)}$
}

\begin{abstract}
RESUMO
A erosão entressulcos acontece pela desagregação originada do impacto das gotas de chuva e pelo transporte do escoamento superficial, por arraste e suspensão das partículas superficiais do solo desagregadas, onde se encontram a matéria orgânica e os nutrientes fundamentais para a produção agrícola. O trabalho objetivou avaliar o efeito de diferentes coberturas do solo em área de cultivo de cana-de-açúcar sob o escoamento superficial na erosão entressulcos. As condições avaliadas foram: solo descoberto; resíduo em contato direto com o solo; dossel da cana-de-açúcar e efeito somado do dossel da cana-de-açúcar e do resíduo em contato com o solo, para três e 12 meses após o corte da cana-planta. Os regimes de escoamento na erosão entressulcos foram laminar lento, e a erodibilidade para o Argissolo Vermelho-Amarelo foi de $1,87 \times 10^{6} \mathrm{~kg} \mathrm{~s} \mathrm{~m}^{-4}$, por conta da presença de mica e caulinita. O resíduo da cana em contato direto com o solo destacou-se no aumento da rugosidade hidráulica, e o dossel pela interceptação da chuva que retardou o início do escoamento superficial, possibilitando maiores taxas de infiltração de água no solo e menores taxas da erosão entressulcos.
\end{abstract}

Termos de indexação: erosão hídrica, erodibilidade do solo, regime do escoamento, chuva simulada.

\footnotetext{
(1) Parte da Tese de Mestrado do primeiro autor, realizada sob a orientação do segundo autor, no Programa de Pós-Graduação em Ciência do Solo, Universidade Federal Rural de Pernambuco - UFRPE. Com recursos da CAPES. Recebido para publicação em março de 2005 e aprovado em abril de 2006.

(2) Doutorando do Programa de Pós-Graduação em Ciência do Solo da Universidade Federal Rural de Pernambuco - UFRPE. CEP 52171-900 Recife (PE). Bolsista do CNPq. E-mail: sabezerra@hotmail.com

(3) Professor do Programa de Pós-Graduação em Ciência do Solo, Departamento de Agronomia, UFRPE. E-mail: cantalic@terra.com.br
} 


\title{
SUMMARY: INTERRILL EROSION UNDER DIFFERENT CONDITIONS OF SOIL COVER OF SUGARCANE
}

\begin{abstract}
Interrill erosion occurs as a result of detachment of soil surface particles caused by raindrop impact and their transportation by overland flow (drag and suspension), which contain the organic matter and nutrients that are essential for agricultural production. An experiment was carried out to evaluate the effect of different soil cover types on the overland flow in interrill erosion in an area of sugarcane cultivation. The following situations were evaluated: bare soil; sugarcane straw mulch; sugarcane canopy cover; sugarcane canopy cover + sugarcane straw mulch three and 12 months after sugarcane harvest. The laminar flow regimes were slow and interrill soil erodibility of the Red-Yellow Argisol was $1.87 \times 10^{6} \mathrm{~kg} \mathrm{~s} \mathrm{~m}^{-4}$ due to the occurrence of kaolinite and mica. Sugarcane straw mulch increased hydraulic roughness, while the standing sugarcane crop intercepted rain and delayed the start of overland flow, increasing water infiltration and decreasing interrill erosion rates.
\end{abstract}

Index terms: water erosion, soil erodibility, flow regime, simulated rain.

\section{INTRODUÇÃO}

A erosão é uma das formas mais prejudiciais de degradação do solo, uma vez que reduz a capacidade produtiva das culturas, além de causar sérios danos ambientais, tais como: assoreamento e poluição das fontes de água (Zartl et al., 2001; Cogo et al., 2003). Para Romkens et al. (2001), a erosão do solo é um fenômeno complexo, que envolve a desagregação e o transporte das partículas de solo, a infiltração da água no solo, o armazenamento de parte da água precipitada e o escoamento superficial. A magnitude relativa e a importância desses processos dependem de um elenco de fatores, a saber: clima, solo, topografia, práticas de manejo do solo e cultura, práticas conservacionistas, condições antecedentes de umidade e tamanho da área considerada.

Segundo Meyer et al. (1975), o processo erosivo tem seu início com o impacto direto das gotas de chuva, provocando a desagregação do solo, que, para Cassol \& Lima (2003), decorre da energia cinética das gotas, que exercem forças de pressão e cisalhamento no ponto de impacto. Os processos primários da erosão em entressulcos são a desagregação pelo impacto das gotas de chuva e o transporte pelo fluxo laminar raso (Agassi \& Bradford, 1999), dependendo a resistência do solo a tais processos da resposta do solo ao impacto, ao fluxo laminar, das mudanças na infiltração, rugosidade e resistência ao início de movimento e transporte das partículas (Albuquerque et al., 2002; Kuhn \& Bryan, 2004). As partículas desagregadas podem obstruir os poros e causar o selamento da superfície do solo, com redução da taxa de infiltração de água e aumento do escoamento superficial ou enxurrada e conseqüente perda de matéria orgânica e diminuição da fertilidade do solo, à medida que a intensidade da chuva supera a infiltração, retenção e detenção superficial (Meyer et al., 1975; Hudson, 1995; Mermut et al., 1997).
A compreensão dos fatores que integram o processo de erosão e a quantificação das perdas do solo serve como princípio na elaboração de medidas que visem a maximizar o uso dos recursos hídricos disponíveis e evitar os efeitos negativos decorrentes da produção, transporte e deposição de sedimentos (Paiva et al., 2001).

Neste sentido, o presente trabalho objetivou avaliar o efeito de diferentes coberturas do solo em área de cultivo de cana-de-açúcar sob o escoamento superficial na erosão entressulcos.

\section{MATERIAL E MÉTODOS}

Os ensaios foram desenvolvidos na Estação Experimental de Cana-de-açúcar da Universidade Federal Rural de Pernambuco, localizada no Município de Carpina, distando $63 \mathrm{~km}$ do Recife, em duas etapas: a primeira realizou-se no terço médio de uma pendente de um talhão com declividade média de $13 \%$ e cultivada com cana-de-açúcar variedade SP791011 no $3^{\circ}$ mês de seu desenvolvimento, onde foram instaladas as parcelas experimentais de $3 \mathrm{~m}^{2}(1 \times 3 \mathrm{~m})$ divididas em três blocos, delimitadas por chapas de alumínio de $15 \mathrm{~cm}$ de altura e fixadas no solo a uma profundidade de $8 \mathrm{~cm}$ com a maior dimensão no sentido do declive, as quais dispunham, na sua parte inferior, de uma calha coletora para a amostragem da enxurrada. O experimento foi instalado, de acordo com o Sistema Brasileiro de Classificação de Solos (Embrapa, 1999) em um Argissolo Vermelho-Amarelo textura média argilosa e profundidade de $2 \mathrm{~m}$ (Alves \& Ribeiro, 1995). As parcelas experimentais receberam os seguintes tratamentos: T1 - Solo descoberto, com uma aração e uma gradagem, no sentido do maior declive; T2 - Efeito isolado do dossel da cana-de-açúcar; T3 - Efeito do dossel da cana-de-açúcar + efeito do resíduo (palha); T4 - Efeito isolado do resíduo. 
A segunda etapa foi realizada com o cultivar de cana-de-açúcar variedade RB-83102, de porte e desenvolvimento semelhante a SP-791011, no seu $12^{\circ}$ mês de desenvolvimento, sob um solo classificado de acordo com o Sistema Brasileiro de Classificação de Solos (Embrapa, 1999) como um Argissolo Amarelo também textura média argilosa, profundidade de $2 \mathrm{~m}$ e características físicas semelhantes às do Argissolo Vermelho-Amarelo, conforme Alves \& Ribeiro (1995). Utilizaram-se parcelas de 4,29 $\mathrm{m}^{2}(3,3 \times 1,3 \mathrm{~m})$, para as avaliações com cobertura do dossel da cana, de acordo com a área de cobertura das folhas da cana-de-açúcar, e $3 \mathrm{~m}^{2}$ (3 x $1 \mathrm{~m}$ ), para as avaliações com resíduos da palha da cana-de-açúcar, divididas em três blocos. As parcelas experimentais receberam os mesmos tratamentos da primeira etapa, exceto o T1.

Para geração da chuva e do escoamento superficial, utilizou-se um simulador de chuvas, construído de acordo com as especificações apresentadas por Meyer \& Harmon, (1979), equipado com um bico aspersor tipo Veejet 80-150 com diâmetros internos de 1/2 polegada, que reproduz uma distribuição de tamanho de gotas e níveis de energia cinética próximos aos das chuvas naturais, que, de acordo com Wischmeier \& Smith (1978), é de 0,294 MJ ha ${ }^{-1} \mathrm{~mm}^{-1}$ e de $17,64 \mathrm{MJ} \mathrm{ha}^{-1}$, para os 60 min de teste. O simulador de chuvas ficou a $3,1 \mathrm{~m}$ acima da superfície do solo na $1^{a}$ etapa de realização dos testes e a $5,7 \mathrm{~m}$ de altura na $2^{\text {a }}$ etapa, com o bico operando a uma pressão de saída de $41 \mathrm{Kpa}$, verificada com o auxílio de um manômetro. As intensidades médias das chuvas simuladas foram de $103 \mathrm{~mm} \mathrm{~h}^{-1}$, para a $1^{\mathrm{a}}$ etapa, e de $100 \mathrm{~mm} \mathrm{~h}^{-1}$, para $2^{\mathrm{a}}$ etapa, aferidas utilizando-se de 10 pluviômetros colocados ao acaso ao lado da área útil das parcelas experimentais. A estação experimental da UFRPE em Carpina-PE apresenta chuvas com intensidades médias de $60 \mathrm{~mm} \mathrm{~h}^{-1} \mathrm{e}$ picos de intensidades de $85 \mathrm{~mm} \mathrm{~h}^{-1}$, de acordo com Koffler \& Lima (1986).

\section{Determinação das taxas de erosão entressul- $\cos$}

As taxas de perdas de solo e a concentração de sedimentos foram determinadas pela pesagem do material, coletado durante 10 segundos em potes plásticos com capacidade de $1 \mathrm{~L}$, em intervalos de $5 \mathrm{~min}$. Aos potes, após pesagem, adicionaram-se $5 \mathrm{~mL}$ de sulfato de $\mathrm{Al}$ e K P.A. de solução com concentração de $50 \mathrm{~g} \mathrm{~L}^{-1}$, para deposição das partículas. Após 24 h, o sobrenadante foi succionado e os potes levados para secagem em estufa a $65{ }^{\circ} \mathrm{C}$ e para posterior quantificação da massa de solo seco. A relação entre a massa de solo seco e a massa de mistura águasedimento foi expressa pela concentração de sedimentos em $\mathrm{kg} \mathrm{L}^{-1}$.

As taxas de desagregação entressulcos do solo (Di) foram determinadas por meio da expressão:

$$
\mathrm{Di}=\frac{\mathrm{Mss}}{\mathrm{A} \cdot \mathrm{Dc}}
$$

em que: Mss = massa do solo seco desagregado (kg), A = área da parcela $\left(\mathrm{m}^{2}\right)$ e $\mathrm{D}_{\mathrm{c}}=$ duração da coleta em (s). As perdas de solo foram obtidas por meio da seguinte equação:

$$
\mathrm{Ps}=\frac{\sum(\mathrm{Q} \cdot \mathrm{Cs} \cdot \mathrm{t})}{\mathrm{A}}
$$

em que $\mathrm{Ps}=$ perdas de solo $\left(\mathrm{kg} \mathrm{m}^{-2}\right) ; \mathrm{Q}=\operatorname{vazão}\left(\mathrm{L} \mathrm{s}^{-1}\right)$; $\mathrm{Cs}_{\mathrm{s}}=$ concentração de sedimentos $\left(\mathrm{kg} \mathrm{L}^{-1}\right) ; \mathrm{t}=$ intervalo entre as coletas (300 s); A = área da parcela $\left(\mathrm{m}^{2}\right)$.

\section{Características hidráulicas do escoamento superficial}

A descarga líquida (q), em $\mathrm{m}^{3} \mathrm{~s}^{-1}$, foi determinada pela medição do volume de enxurrada coletado na extremidade da calha coletora em provetas, durante o tempo cronometrado, e dividido pela largura da parcela, para expressão em $\mathrm{m}^{2} \mathrm{~s}^{-1}$. A velocidade superficial do escoamento $\left(V_{\mathrm{S}}\right)$, gerado a partir da chuva simulada, foi determinada com a tomada de tempo gasto, efetuada por meio de um cronômetro, para que um corante azul de metileno percorresse a distância entre dois pontos fixos na parcela, sendo expresso em $\mathrm{m} \mathrm{s}^{-1}$. Essas determinações foram realizadas em intervalos de cinco minutos e coincidentes com as determinações de descarga líquida, a partir da formação e deslocamento da lâmina de escoamento. As velocidades médias do escoamento (V) foram determinadas pelo produto das velocidades superficiais do escoamento por um fator de correção $(\alpha=2 / 3)$, conforme Farenhorst \& Bryan (1995) e Cassol et al. (2004). A altura da lâmina do escoamento (h) foi obtida a partir da equação (3), derivada por Woolhiser \& Liggett (1967) e Singh (1983) para solução cinemática das equações de Saint-Venant:

$$
\mathrm{h}=\frac{\mathrm{q}}{\mathrm{V}}
$$

em que: $q$ = descarga líquida por unidade de largura, em $\mathrm{m}^{2} \mathrm{~s}^{-1}, \mathrm{~V}=$ velocidade média do escoamento, em $\mathrm{m} \mathrm{s}^{-1}, \mathrm{e} \mathrm{h}=$ altura da lâmina de escoamento, em $\mathrm{m}$. $\mathrm{O}$ número de Reynolds (Re) foi obtido por meio da equação (4) apresentada por Simons \& Senturk (1992):

$$
\mathrm{R}_{\mathrm{e}}=\frac{\mathrm{Vh}}{\mathrm{v}}
$$

em que $\operatorname{Re}=$ número de Reynolds, adimensional; $v=$ viscosidade cinemática da água $\left(\mathrm{m}^{2} \mathrm{~s}^{-1}\right)$. A viscosidade cinemática foi determinada com a utilização da equação (5), segundo Julien (1995), sendo a temperatura $\left({ }^{\circ} \mathrm{C}\right)$ aferida por meio de um termômetro em cada teste.

$$
v=\left[1,14-0,031(\mathrm{~T}-15)+0,00068(\mathrm{~T}-15)^{2} \times 10^{-6}\right.
$$

em que $\mathrm{T}=$ temperatura da água $\mathrm{em}^{\circ} \mathrm{C}$. $\mathrm{O}$ número de Froude (Fr) foi obtido pela expressão (6), de acordo com Simons \& Senturk (1992): 


$$
F_{r}=\frac{V}{\sqrt{g h}}
$$

em que $\mathrm{F}_{\mathrm{r}}=$ número de Froude, adimensional; $\mathrm{e} \mathrm{g}=$ aceleração da gravidade $\left(\mathrm{m} \mathrm{s}^{-2}\right)$. A partir dos números de Reynolds e Froude, foram obtidos os regimes de escoamento gerados a partir das chuvas simuladas. A rugosidade hidráulica ao escoamento superficial foi obtida pelo cálculo do coeficiente de Fricção de Darcy-Weisbach:

$$
f=\frac{8 \mathrm{ghS}}{\mathrm{V}^{2}}
$$

em que $f=$ fator de fricção ou de perda de carga (adimensional); $\mathrm{S}=$ inclinação do declive $\left(\mathrm{m} \mathrm{m}^{-1}\right) ; \mathrm{g}=$ aceleração da gravidade $\left(\mathrm{m} \mathrm{s}^{-2}\right) ; \mathrm{h}=$ altura da lâmina do escoamento $(\mathrm{m})$; e $\mathrm{V}=$ velocidade média do escoamento $\left(\mathrm{m} \mathrm{s}^{-1}\right)$.

\section{Erodibilidade do solo}

A erodibilidade entressulcos do solo $(K i)$ foi determinada utilizando-se a equação (8), na qual as taxas máximas de desagregação do solo foram obtidas nos últimos $30 \mathrm{~min}$ de avaliação, conforme recomendado por Elliot et al. (1989), para cada uma das repetições dos tratamentos com o solo descoberto.

$$
K i=\frac{D i}{I^{2} . S f}
$$

em que $K i=$ erodibilidade entressulcos do solo $\left(\mathrm{kg} \mathrm{s} \mathrm{m}{ }^{-4}\right) ; D i=$ taxa de desagregação entressulcos do solo $\left(\mathrm{kg} \mathrm{m}^{-2} \mathrm{~s}^{-1}\right) ; I=$ intensidade da chuva $\left(\mathrm{m} \mathrm{s}^{-1}\right)$; $S_{f}=$ fator de correção para o declive (adimensional), dado pela equação:

$$
\mathrm{S}_{f}=1,05-0,85 \exp ^{(-4 \operatorname{sen}(\theta))}
$$

em que $\theta$ é o ângulo do declive (em graus). Este fator $S_{f}$ é de 0,2, para declive plano; de 1, para declive de $45^{\circ}$, e o valor máximo é de 1,05 , para declives de $90^{\circ}$.

\section{Quantificação da percentagem de cobertura do solo pelo método fotográfico}

A percentagem de cobertura do solo foi determinada por meio do método de Mannering, descrito por Bezerra et al. (2002), que utiliza a projeção fotográfica de uma moldura com a cobertura vegetal da área. Inicialmente, construiu-se uma moldura de madeira nas dimensões de $76 \mathrm{~cm}$ de largura por $51 \mathrm{~cm}$ de comprimento, a qual foi, então, montada sobre uma área representativa das parcelas. Em seguida, foi feita a fotografia, enquadrando-se a moldura no visor da câmara digital. Utilizaram-se um computador e um Data Show, projetando-se as molduras fotografadas em um quadro-padrão (Figura 1) fixado numa tela.

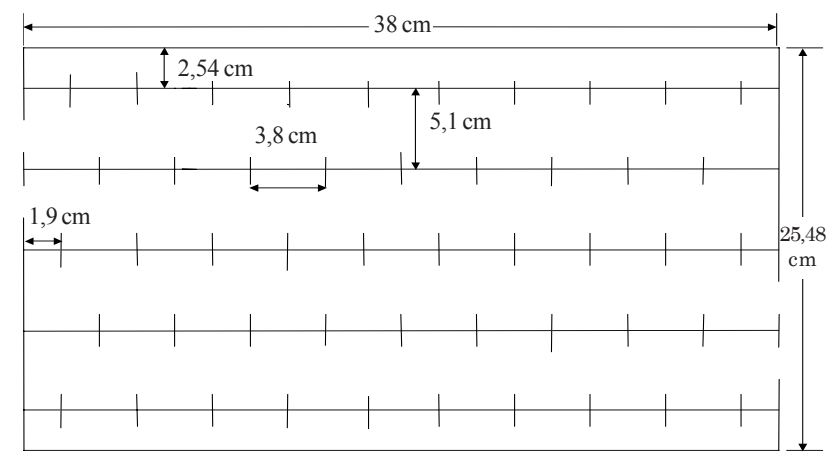

Figura 1. Quadro-padrão utilizado para determinar a percentagem de cobertura do solo, com a projeção fotográfica sobre o mesmo.

Com a soma da contagem das intersecções entre as linhas retas horizontais e verticais com os pontos de cobertura vegetal da superfície (copa e, ou, resíduo) projetados, tem-se a percentagem total de cobertura vegetal, representando cada ponto de intersecção $2 \%$, pois 50 são os pontos de intersecção.

Os resultados foram submetidos à análise de variância e de comparação de médias pelo teste de Tukey a $5 \%$, em um delineamento em blocos ao acaso, utilizando-se o programa estatístico SAS - Statistical Analitical System (SAS, 1998). Como as variáveis de perdas de solo e cobertura do solo são quantitativas, utilizou-se a regressão na análise desses dados. A análise de comparação entre as médias dos resultados do fator de fricção $(f)$ foi realizada pelo teste de Duncan a $5 \%$.

\section{RESULTADOS E DISCUSSÃO}

\section{Caracterização hidráulica do escoamento superficial}

Os regimes de escoamento em todas as condições criadas pela cultura da cana-de-açúcar foram laminar lento ou subcrítico, como indicado pelos valores de $\mathrm{Re}<500$ e $\mathrm{Fr}<1$, assim como os valores de descarga líquida (q) na ordem de grandeza de $10^{-5} \mathrm{~m}^{2} \mathrm{~s}^{-1}$ e altura de lâmina de $10^{-3}$ e $10^{-4} \mathrm{~m}$ (Quadro 1), juntamente com o regime de escoamento, caracterizado por baixos valores do número de Reynolds, estão em acordo com a magnitude de lâminas de escoamento obtidas por Guy et al. (1990), Cantalice (2002) e Cassol et al. (2004), permitindo inferir que ocorreu um escoamento característico de erosão em entressulcos. Pôde-se perceber claramente a existência de uma lâmina de escoamento distribuída em toda parcela (Figura 2), apesar de ser ela perpassada pelos resíduos vegetais da cana, que tem uma altura visivelmente maior que a lâmina, validando, dessa forma, a utilização da equação (3). 
Quadro 1. Características hidráulicas do escoamento ocasionado pela chuva simulada para as diferentes formas de cobertura vegetal da cana-de-açúcar aos três e 12 meses de desenvolvimento

\begin{tabular}{|c|c|c|c|c|c|c|c|c|}
\hline Tratamento & CS & $\mathbf{q}$ & V & $\mathbf{h}$ & v & $\mathbf{R}_{\mathbf{e}}$ & $\mathbf{F}_{\mathbf{r}}$ & $\log f$ \\
\hline & $\mathrm{m}^{2} \mathrm{~m}^{-2}$ & $\mathrm{~m}^{2} \mathrm{~s}^{-1}$ & $\mathrm{~m} \mathrm{~s}^{-1}$ & $\mathrm{~m}$ & $\mathrm{~m}^{2} \mathrm{~s}^{-1}$ & 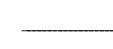 & - adim & 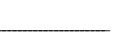 \\
\hline & \multicolumn{8}{|c|}{ Três meses } \\
\hline SD & 0,00 & $8,705 \times 10^{-5} \mathrm{a}$ & $0,06689 \mathrm{a}$ & $1,301 \times 10^{-3} \mathrm{a}$ & $8,28 \times 10^{-7}$ & 105,13 & 0,5921 & $0,469 \mathrm{a}$ \\
\hline $\mathrm{R}$ & 0,18 & $8,818 \times 10^{-5} \mathrm{a}$ & $0,05518 \mathrm{a}$ & $1,598 \times 10^{-3} \mathrm{a}$ & $8,28 \times 10^{-7}$ & 106,50 & 0,4407 & $0,580 \mathrm{a}$ \\
\hline $\mathrm{D}$ & 0,30 & $5,705 \times 10^{-5} \mathrm{a}$ & $0,05573 \mathrm{a}$ & $1,024 \times 10^{-3} \mathrm{a}$ & $8,21 \times 10^{-7}$ & 69,42 & 0,5561 & $0,333 \mathrm{a}$ \\
\hline \multirow[t]{2}{*}{$\mathrm{D}+\mathrm{R}$} & 0,51 & $5,723 \times 10^{-5} \mathrm{a}$ & $0,04538 \mathrm{a}$ & $1,261 \times 10^{-3} \mathrm{a}$ & $8,28 \times 10^{-7}$ & 69,12 & 0,4080 & $0,700 \mathrm{a}$ \\
\hline & \multicolumn{8}{|c|}{12 meses } \\
\hline $\mathrm{R}$ & 0,83 & $9,376 \times 10^{-5} \mathrm{a}$ & $0,0516 \mathrm{a}$ & $1,818 \times 10^{-3} \mathrm{a}$ & $8,18 \times 10^{-7}$ & 114,61 & 0,3862 & $0,491 \mathrm{a}$ \\
\hline $\mathrm{D}^{(1)}$ & 0,48 & $6,202 \times 10^{-5} \mathrm{a}$ & $0,0741 \mathrm{a}$ & $8,373 \times 10^{-4} \mathrm{a}$ & $8,42 \times 10^{-7}$ & 73,66 & 0,8173 & $0,005 \mathrm{a}$ \\
\hline $\mathrm{D}+\mathrm{R}^{(1)}$ & 0,85 & $2,981 \times 10^{-5} \mathrm{a}$ & $0,0468 \mathrm{a}$ & $6,369 \times 10^{-4} \mathrm{a}$ & $8,18 \times 10^{-7}$ & 36,44 & 0,5921 & $0,598 \mathrm{a}$ \\
\hline
\end{tabular}

$\overline{\mathrm{SD}}=$ solo descoberto; $\mathrm{D}$ = efeito isolado do dossel da cana-de-açúcar; $\mathrm{D}+\mathrm{R}$ = efeito do dossel da cana-de-açúcar + resíduo (palha); $\mathrm{R}$ = resíduo (palha) da cana-de-açúcar. Valores seguidos da mesma letra, na mesma coluna, não diferem entre si a $5 \%$; Valores de $f$, seguidos da mesma letra, na mesma coluna, não diferem estatisticamente pelo teste de Duncan a $5 \%$ de probabilidade. ${ }^{1}$ Valores médios de duas repetições. Cobertura do solo (CS), descarga líquida (q), velocidade média do escoamento (V), altura da lâmina (h), N. de Reynolds (Re), N. de Froude (Fr), viscosidade cinemática (v), declive (S) e coeficiente de rugosidade - DarcyWeisbach (f). Valores médios de três repetições.

Ainda no quadro 1, observa-se que os valores de rugosidade hidráulica ( $f$ ) não diferiram, significativamente, entre os tratamentos, mas são necessárias algumas considerações quanto ao preparo do solo e à rugosidade criada pelas diferentes formas de cobertura vegetal da cana-de-açúcar. A rugosidade hidráulica do solo descoberto, que foi imediatamente avaliada após o preparo do solo, igualou-se à rugosidade hidráulica originada com os diferentes tipos de cobertura com resíduos ou plantas, que só foram avaliadas depois, quando certamente a rugosidade do solo descoberto já estaria diminuída pelo impacto das chuvas naturais que se sucederam. A rugosidade do solo descoberto ocorreu por conta das operações de preparo (uma aração e uma gradagem) que, ao revolverem o solo, acabaram por originar torrões e grandes agregados na superfície do solo, sendo essa uma rugosidade de forma. Tal rugosidade decresceu com o decorrer do tempo, graças ao efeito de impactos sucessivos das gotas de chuva sobre a superfície do solo (Barcelos et al., 1999; Johnson et al., 1979), o que a caracteriza como rugosidade transitória.

O efeito somado dos tratamentos da palha em contato direto com o solo e do dossel da cana-deaçúcar $(\mathrm{D}+\mathrm{R})$ proporcionou maior rugosidade hidráulica que o efeito isolado do dossel da cana aos três e 12 meses (Quadro 1), pelo fato de o resíduo estar em maior contato com o escoamento, aliado ao efeito do dossel em interceptar a chuva e retardar o início do escoamento. Nota-se que o aumento da cobertura do solo proporcionou o aumento na resistência ao escoamento promovido pela rugosidade de forma, originado pela presença da palha na superfície, aumentando as forças viscosas, elevando a altura da lâmina de escoamento e aumento das forças da gravidade, diminuindo o número de Froude, tal como também observado por Cassol et al. (2004).

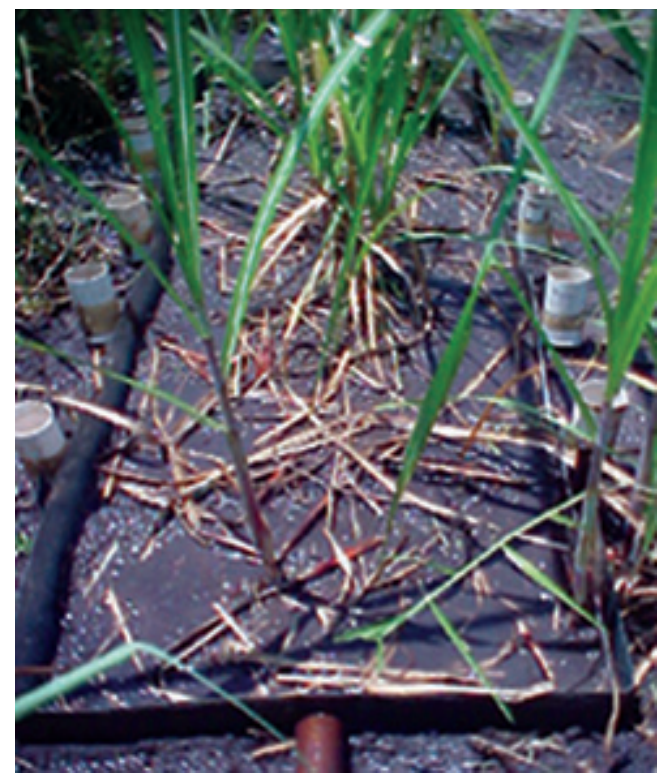

Figura 2. Aspecto do escoamento pouco espesso em regime laminar lento na cultura da cana-deaçúcar com três meses de desenvolvimento. 
O efeito isolado do resíduo após três meses de contato direto com a superfície do solo foi o que proporcionou a formação de maior altura de lâmina de escoamento, apesar de ter proporcionado apenas $18,5 \%$ de cobertura do solo, enquanto o efeito isolado do dossel, com $30 \%$ de cobertura do solo, proporcionou a menor altura de lâmina (Quadro 1). Essa diferenciação na altura do escoamento está relacionada com o tipo da cobertura vegetal, pois o resíduo em contato direto com o solo também está em contato direto com o escoamento, motivo pelo qual interfere na altura da lâmina, enquanto o dossel não. Esse fato é comprovado pelo maior valor de rugosidade para o efeito isolado do resíduo, comparando-se com o efeito isolado do dossel. Para o caso do efeito somado do dossel + resíduo com $51 \%$ de cobertura do solo, novamente o efeito do contato direto do resíduo se sobrepôs, pois, descontando a percentagem de cobertura do dossel (30\%), fica-se com $21 \%$ para o efeito do resíduo, embora o valor de $f$ tenha sido o mais elevado. Esse elevado valor de $f$ deve-se também ao efeito do dossel que promove maior interceptação e, conseqüentemente maior infiltração (Figura 3), retardando, assim, o início do escoamento e diminuindo a altura da lâmina e a descarga líquida (Quadro 1).

Para a segunda etapa do trabalho, observa-se, novamente, que o efeito somado dos tratamentos do dossel e do resíduo em contato com o solo $(D+R)$ apresentou descarga líquida diferenciada, tendo em vista a sua maior interceptação vegetal, o que retardou o início do escoamento superficial e aumentou a infiltração durante o teste (Figura 4). Observou-se que o resíduo em contato direto com o solo proporcionou taxas de infiltração comparáveis com as taxas de infiltração no solo descoberto depois de três meses do início do experimento, determinando maior escoamento superficial (Figura 4). O resíduo em contato direto com o solo, apesar de proporcionar $83 \%$ de cobertura da superfície do solo, apresentou

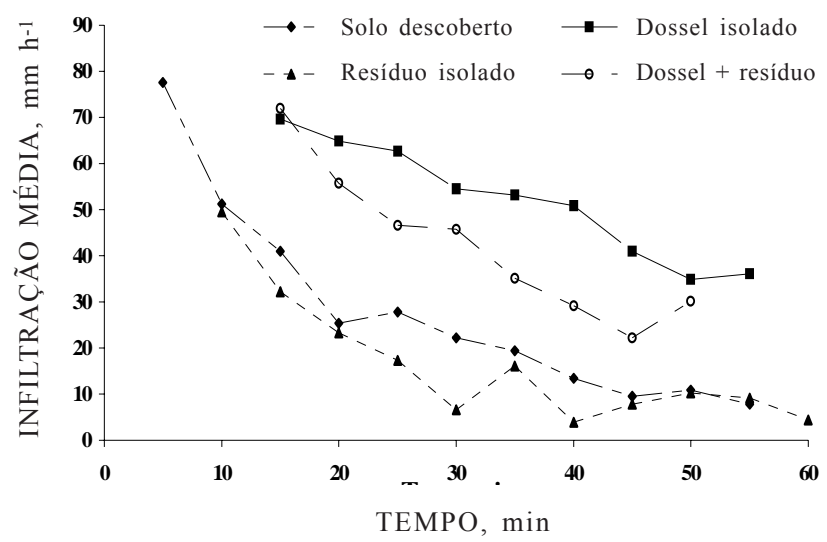

Figura 3. Taxas de infiltração, obtidas pelo método do infiltrômetro aspersor, para as diferentes formas de cobertura vegetal da cana-de-açúcar no terceiro mês de desenvolvimento.

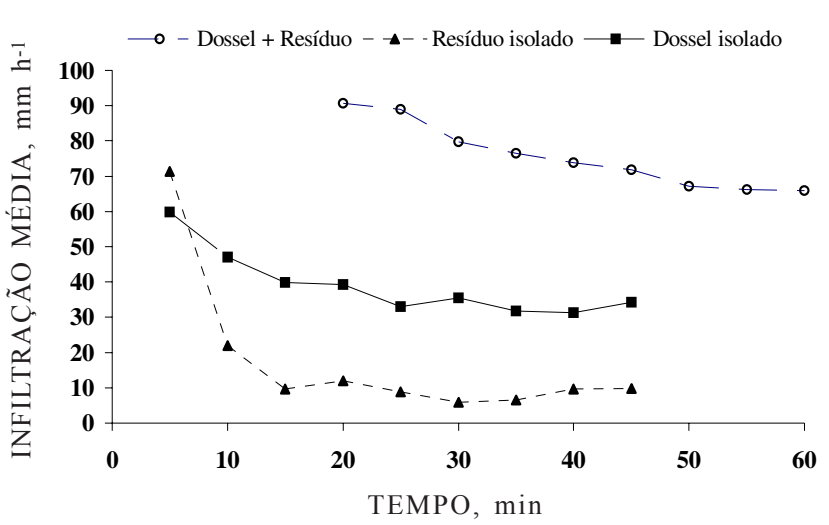

Figura 4. Taxas de infiltração, obtidas pelo método do infiltrômetro aspersor, para as diferentes formas de cobertura vegetal da cana-de-açúcar no $12^{\circ}$ mês de desenvolvimento.

baixas taxas de infiltração de água, o que se deve à forma alongada das folhas da cana-de-açúcar com até $80 \mathrm{~cm}$ de comprimento e de 1 a $2 \mathrm{~cm}$ de largura, por onde a água escoou para fora da área da parcela e, dessa forma, não infiltrou no solo. Esta constatação está de acordo com Cogo (1981), que ressaltou que os fatores que determinam as diferenças de cobertura do solo entre os resíduos culturais são do tipo, forma, quantidade, distribuição sobre a superfície, estádio de decomposição e forma de preparo do solo.

\section{Taxas de erosão do solo}

Com as plantas de cana-de-açúcar aos três meses de desenvolvimento, foi observado que as menores taxas de desagregação foram obtidas para o efeito somado do dossel da cana-de-açúcar + resíduo em contato direto com o solo, com valores da ordem de grandeza de $10^{-5} \mathrm{~kg} \mathrm{~m}^{-2} \mathrm{~s}^{-1}$, para uma cobertura de solo de $51 \%$. Em seguida, tem-se o efeito do dossel da cana-de-açúcar com a taxa de desagregação de $10^{-4} \mathrm{~kg} \mathrm{~m}^{-2} \mathrm{~s}^{-1}$, com percentagem de cobertura do solo de 30 \% (Quadro 2). As taxas de desagregação de solo, nas duas etapas, na ordem de $10^{-6}$ a $10^{-4} \mathrm{~kg} \mathrm{~m}^{-2} \mathrm{~s}^{-1}$, são equivalentes às de idade de início do experimento, obtidas por Guy et al. (1990) e Cantalice (2002), o que, conjuntamente com a hidráulica dos escoamentos ensaiados, permite concluir que ocorreu erosão em entressulcos. Aos 12 meses, percebeu-se também a ocorrência de taxas de desagregação de solo decrescentes com o aumento da percentagem de cobertura do solo, onde o efeito isolado do dossel apresentou a maior taxa de desagregação, da ordem de $10^{-4} \mathrm{~kg} \mathrm{~m}^{-2} \mathrm{~s}^{-1}$, para uma cobertura de $48 \%$, o efeito isolado resíduo da ordem de $10^{-5} \mathrm{~kg} \mathrm{~m}^{-2} \mathrm{~s}^{-1}$, para uma cobertura de $83 \%$, e o efeito somado do dossel + resíduo, da ordem de $10^{-6} \mathrm{~kg} \mathrm{~m}^{-2} \mathrm{~s}^{-1}$, para uma cobertura do solo de $85 \%$. O mesmo foi observado por Cassol et al. (2004) que, com o aumento das doses de palha (aumento da cobertura), obtiveram taxas de desagregação decrescentes, chegando a uma grandeza de $10^{-5} \mathrm{~kg} \mathrm{~m}^{-2} \mathrm{~s}^{-1}$. 
Quadro 2. Taxas de desagregação entressulcos do solo $\left(D_{i}\right)$, observadas para as diferentes formas de cobertura vegetal da cana-de-açúcar no $3^{\circ} \mathrm{e}$ no $12^{\circ}$ mês de desenvolvimento

\begin{tabular}{lll}
\hline Tratamento & Declividade & $D_{\mathrm{i}}$ \\
\hline
\end{tabular}

\begin{tabular}{lrr}
\hline & $\mathrm{m} \mathrm{m}^{-1}$ & \multicolumn{2}{c}{$\mathrm{kg} \mathrm{m}^{-2} \mathrm{~s}^{-1}$} \\
& \multicolumn{2}{c}{ Três meses } \\
$\mathrm{SD}$ & 0,13 & $9,413 \times 10^{-4} \mathrm{a}$ \\
$\mathrm{D}$ & 0,09 & $3,449 \times 10^{-4} \mathrm{~b}$ \\
$\mathrm{D}+\mathrm{R}$ & 0,08 & $3,013 \times 10^{-4} \mathrm{~b}$ \\
& 0,10 & $9,381 \times 10^{-5} \mathrm{~b}$ \\
& \multicolumn{2}{c}{12 meses } \\
$\mathrm{R}$ & 0,07 & $4,856 \times 10^{-5} \mathrm{~b}$ \\
$\mathrm{D}^{(1)}$ & 0,09 & $1,481 \times 10^{-4} \mathrm{~b}$ \\
$\mathrm{D}+\mathrm{R}^{(1)}$ & 0,09 & $6,923 \times 10^{-6} \mathrm{~b}$
\end{tabular}

$\mathrm{SD}=$ solo descoberto $\mathrm{D}=$ efeito isolado do dossel da cana-deaçúcar; $\mathrm{D}+\mathrm{R}$ = efeito do dossel da cana-de-açúcar + resíduo (palha); $\mathrm{R}=$ resíduo (palha) da cana-de-açúcar (valores médios de duas repetições). Valores seguidos da mesma letra, na mesma coluna, não diferem entre si a $5 \%$.

Estes resultados demonstram que, quanto maiores as percentagens de cobertura do solo, proporcionadas pelas diferentes formas de cobertura da cana-deaçúcar, menores as taxas de desagregação, decorrentes do menor impacto das gotas de chuva na superfície do solo, diminuindo, assim, a desagregação das partículas da camada superficial do solo. O tratamento em que houve o efeito somado do dossel + resíduo (palha) em contato direto com o solo aos 12 meses de cultivo (Quadro 2) foi o que apresentou as menores taxas de perdas de solo, cabendo ao resíduo em contato direto com o solo o aumento da rugosidade e a diminuição da ação do impacto das gotas de chuva, enquanto o dossel contribuiu com o aumento na taxa de infiltração de água no solo pela interceptação vegetal promovida. Assim, o efeito conjunto do resíduo e do dossel proporcionou a redução em torno de $95 \%$ nas taxas de desagregação do solo, em relação ao efeito isolado do dossel aos 12 meses.

Comparando às taxas de desagregação do solo para o efeito conjunto do dossel e do resíduo aos 12 meses com o solo descoberto, verificou-se uma redução aproximada de $99 \%$. Justifica-se a maior taxa de desagregação para a parcela sem cobertura pelo fato de ter sido a infiltração mais elevada no início do escoamento (Figura 4), onde o fluxo superficial foi relativamente pequeno, não tendo capacidade para transportar o material desagregado pelo impacto das gotas de chuva. Porém, à medida que a infiltração decresceu e houve um aumento do fluxo sob a superfície, este se tornou capaz de transportar o que foi desagregado anteriormente e o remanescente, aumentando as taxas de desagregação do solo, quando antes havia limitação da capacidade de transporte (Braida \& Cassol, 1999).

Na figura 5, tem-se representada, de forma global e para todo o ciclo fenológico da cana-de-açúcar, a redução nas perdas de solo com o aumento das percentagens de cobertura vegetal, mostrando, embora mais empiricamente, o efeito conjunto de todos tratamentos em dois períodos do ciclo fenológico. As perdas de solo mostraram-se decrescentes com o aumento da cobertura vegetal, indicando a necessidade da cobertura do solo como prática conservacionista para garantir o adequado controle erosivo e, com isso, amenizar o movimento do escoamento superficial, pois, conforme Cogo et al., (2003), a capacidade erosiva das enxurradas é aumentada, principalmente, quando o solo apresenta reduzida cobertura superficial. O controle das perdas de solo proporcionado pelas diferentes formas da cobertura vegetal da cana-de-açúcar foi representado na forma de uma equação de regressão do tipo exponencial, conforme descrito abaixo:

$$
\mathrm{P}_{\mathrm{s}}=22,893 \mathrm{e}^{-4,4256(\mathrm{Cs})}
$$

em que $\mathrm{P}_{\mathrm{s}}$ perdas de solo em $\mathrm{t}$ ha ${ }^{-1}, \mathrm{Cs}=$ cobertura do solo em $\mathrm{m}^{2} \mathrm{~m}^{-2} \mathrm{e}, \mathrm{e}=$ base do logaritmo.

\section{Erodibilidade do solo}

Os valores médios de erodibilidade entressulcos do solo (Ki), para cada um dos ensaios realizados no Argissolo Vermelho-Amarelo distrófico, estão apresentados no quadro 3. Considerando as três repetições do T1 (solo descoberto), os valores de $\mathrm{Ki}$ variaram de $1,39 \times 10^{6}$ a $2,12 \times 10^{6} \mathrm{~kg} \mathrm{~s} \mathrm{~m}^{-4}$. Cantalice (2002) determinou, em condições de laboratório e campo, para um Argissolo Vermelho distrófico típico, um valor de $K i$ de $2,55 \times 10^{6} \mathrm{~kg} \mathrm{~s} \mathrm{~m}^{-4}$ e, para o mesmo solo, porém em campo, Rockenbach (1992) determinou o valor de $3,35 \times 10^{6} \mathrm{~kg} \mathrm{~s} \mathrm{~m}^{-4}$.

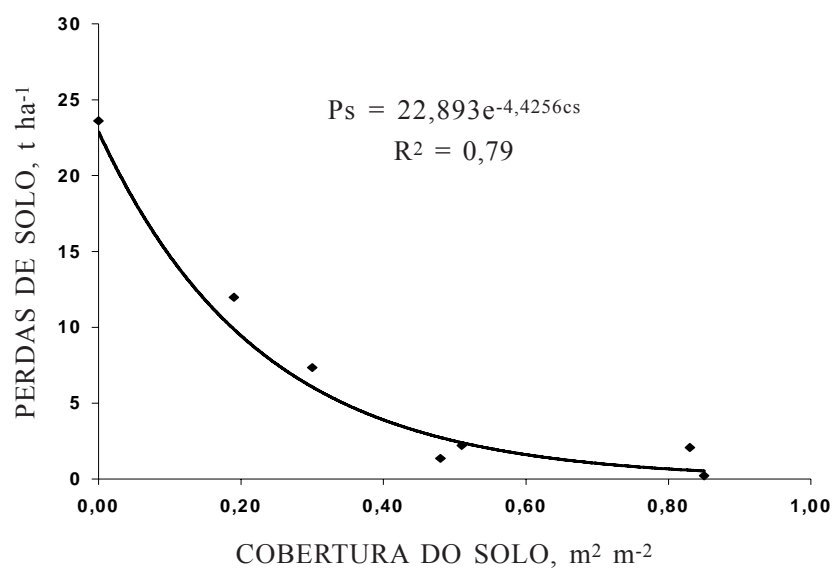

Figura 5. Taxas de perdas de solo, obtidas por diferentes formas de cobertura vegetal da canade-açúcar no $3^{\circ}$ e no $12^{\circ}$ mês de desenvolvimento. 
Quadro 3. Valores médios de erodibilidade entressulcos do solo $\left(\mathrm{K}_{\mathrm{i}}\right)$, para todos os testes realizados em condições de solo descoberto (Argissolo Vermelho-Amarelo Tb distrófico)

\begin{tabular}{cccccc}
\hline Declividade & $\boldsymbol{D}_{\boldsymbol{i}}$ & $\mathbf{I}$ & $\boldsymbol{S}_{\boldsymbol{f}}$ & $\boldsymbol{K}_{\boldsymbol{i}}$ & \multicolumn{1}{c}{ Média } \\
\hline $\mathrm{m} \mathrm{m}^{-1}$ & $\mathrm{~kg} \mathrm{~m}^{-2} \mathrm{~s}^{-1}$ & $\mathrm{~m} \mathrm{~s}^{-1}$ & & \\
0,134 & $1,16 \times 10^{-3}$ & $3,146 \times 10^{-5}$ & 0,5519 & $2,12 \times 10^{6}$ \\
0,157 & $1,07 \times 10^{-3}$ & $2,916 \times 10^{-5}$ & 0,5952 & $2,11 \times 10^{6}$ & $1,39 \times 10^{6}$ \\
0,091 & $5,94 \times 10^{-4}$ & $3,050 \times 10^{-5}$ & 0,4581 & $1,87 \times 10^{6}$ \\
\hline
\end{tabular}

$K_{i}=$ erodibilidade entressulcos do solo; $D_{i}=$ taxa máxima de desagregação entressulcos do solo; $\mathrm{I}=$ intensidade da chuva e $S_{f}=$ fator de correção para o declive.

Esses valores foram mais elevados que o valor obtido neste trabalho, o que se justifica, muito possivelmente, pelo fato de a cana-de-açúcar incrementar o conteúdo de matéria orgânica do solo, que, por sua vez, aumenta a estabilidade dos agregados do solo, bem como pelo menor teor de argila para o Argissolo utilizado por Cantalice (2002) e Rockenbach (1992), que teve $0,2065 \mathrm{~kg} \mathrm{~kg}^{-1}$ de argila, $0,198 \mathrm{~kg} \mathrm{~kg}^{-1}$ de silte e $0,5955 \mathrm{~kg} \mathrm{~kg}^{-1}$ de areia. Braida \& Cassol (1996) encontraram um valor de erodibilidade em entressulcos de $5,10 \times 10^{6} \mathrm{~kg} \mathrm{~s} \mathrm{~m}^{-4}$, também em condições de campo, para um Argissolo Vermelho distrófico arênico, valor ainda mais elevado que o obtido neste trabalho, justificado, também, pelo baixo teor de argila de $0,145 \mathrm{~kg} \mathrm{~kg}^{-1}$, além de $0,101 \mathrm{~kg} \mathrm{~kg}^{-1}$ de silte e $0,755 \mathrm{~kg} \mathrm{~kg}^{-1}$ de areia, enquanto o solo ora estudado apresenta $0,228 \mathrm{~kg} \mathrm{~kg}^{-1}$ de argila, $0,094 \mathrm{~kg} \mathrm{~kg}^{-1}$ de silte e $0,678 \mathrm{~kg} \mathrm{~kg}^{-1}$ de areia.

Com base no que foi comentado, a maior percentagem de argila no solo utilizado no presente trabalho conferiu a este Argissolo erodibilidade do solo de $1,87 \times 10^{6} \mathrm{~kg} \mathrm{~s} \mathrm{~m}^{-4}$, pouco menor que a obtida para o Argissolo utilizado por Cantalice (2002) e bem menor que a obtida para solo utilizado por Braida \& Cassol (1996).

O menor valor de Ki obtido para o Argissolo Vermelho-Amarelo relaciona-se com a fração argila estudada por Alves \& Ribeiro (1995), ao constatarem que a mineralogia da argila é constituída principalmente de mica e caulinita em todo o perfil, conferindo a esse maior resistência à erosão e, conseqüentemente, menor valor de erodibilidade, em relação ao Argissolo Amarelo da mesma área, também estudado por Alves \& Ribeiro (1995), que apresentaram na sua fração argila predominância da caulinita. Também pode ter havido interação com a matéria orgânica, como constatado por Reichert et al. (2001), ao afirmarem que as características intrínsecas dos solos do Brasil, teores de argila e matéria orgânica, justificam as diferenças em valores de erodibilidade entressulcos obtidas.

\section{CONCLUSÕES}

1. Os efeitos somados do dossel e do resíduo da cana-de-açúcar promoveram simultaneamente o aumento da rugosidade hidráulica e dos volumes de interceptação vegetal, determinando as menores lâminas de escoamento superficial e os maiores volumes de infiltração e, assim, proporcionaram as menores taxas de desagregação do solo.

2. De forma global e para todo o ciclo da cultura da cana-de-açúcar, observou-se diminuição das perdas de solo com o aumento das taxas de cobertura de solo.

3. A erodibilidade do solo em entressulcos $(K i)$ do Argissolo Vermelho-Amarelo de $1,87 \times 10^{6} \mathrm{~kg} \mathrm{~s} \mathrm{~m}^{-4}$ foi baixo em relação aos valores de erodibilidade de alguns Argissolos citados, refletindo seu maior teor de argila e a presença de mica e caulinita, conferindolhe maior resistência à erosão.

\section{LITERATURA CITADA}

ALBUQUERQUE, A.W.; LOMBARDI NETO, F.; SRINIVASAN, V.S. \& SANTOS, J.R. Manejo da cobertura do solo e de práticas conservacionistas nas perdas de solo e água em Sumé, PB. R. Bras. Eng. Agric. Amb., 6:136-141, 2002.

ALVES, A.J.O. \& RIBEIRO, M.R. Caracterização e gênese dos solos de uma toposseqüência na microrregião da mata seca de Pernambuco. R. Bras. Ci. Solo, 19:297-305, 1995.

AGASSI, M. \& BRADFORD, J.M. Methodologies for interrill soil erosion studies. Soil Till. Res., 49:277-287, 1999.

BARCELOS, A.A.; CASSOL, E.A. \& DENARDIN, J.E. Infiltração de água em um Latossolo Vermelho-Escuro sob condições de chuva intensa em diferentes sistemas de manejo. R. Bras. Ci. Solo, 23:35-43, 1999.

BEZERRA, S.A.; CANTALICE, J.R.B. \& TARQUI, J.L.Z. Características do escoamento superficial e taxas de erosão em uma área sob cultivo agrícola. In: ENCONTRO NACIONAL DE ENGENHARIA DE SEDIMENTOS, 5.; São Paulo, 2002. Anais. São Paulo, ABRH, 2002. p.403411.

BRAIDA, J.A. \& CASSOL, E.A. Relações da erosão em entressulcos com o tipo e com a quantidade de resíduo vegetal na superfície do solo. R. Bras. Ci. Solo, 23:711$721,1999$. 
BRAIDA, J.A. \& CASSOL, E.A. Erodibilidade em sulcos e em entressulcos de um Podzólico Vermelho-Escuro francoarenoso. R. Bras. Ci. Solo, 20:127-134, 1996.

CANTALICE, J.R.B. Escoamento e erosão em sulcos e em entressulcos em distintas condições de superfície do solo. Porto Alegre, Universidade Federal do Rio Grande do Sul, 2002. 141p. (Tese de Doutorado)

CASSOL, E.A.; CANTALICE, J.R.B.; REICHERT, J.M. \& MONDARDO, A. Escoamento superficial e desagregação o solo em entressulcos em solo franco-argilo-arenoso com resíduos vegetais. Pesq. Agropec. Bras., 39:685-690, 2004.

CASSOL, E.A. \& LIMA, V.S. Erosão em entressulcos sob diferentes tipos de preparo e manejo do solo. Pesq. Agropec. Bras., 38:117-124, 2003.

COGO, N.P.; LEVIEN, R. \& SCHWARZ, R.A. Perdas de solo e água por erosão hídrica influenciadas por métodos de preparo, classes de declive e níveis de fertilidade do solo. R. Bras. Ci. Solo, 27:743-753, 2003.

COGO, N.P. Efeect of residue cover, tillage induced roughness, and slope length on erosion and related parameters. West Lafayett, Purdue University, 1981. 346p.(Tese de Doutorado)

ELLIOT, W.J.; LIEBNOW, A.M.; LAFLEN, J.M. \& KOHL, K.D. A compendium of soil erodibility data from WEPP cropland soil field erodibility experiments $1987 \& 88$. West Lafayette, The Ohio State University, 1989. (NSERL National Soil Erosion Research Laboratory Report, 3)

EMPPESA BRASILEIRA DE PESQUISA AGROPECUÁRIA EMBRAPA. Sistema brasileiro de classificação de solos. Brasília, 1999. 412p.

FARENHORST, A. \& BRYAN, R.B. Particle size distribution of sediment transported by shallow flow. Catena, 25:4762, 1995 .

GUY, B.T.; DICKINSON, W.T. \& RUDRA, R.P. Hydraulics of sediment-landen sheet flow and the influence of simulated rainfall. Earth Surf. Proc. Landf., 15:101-118, 1990.

HUDSON, N. Soil conservation. 3.ed. Iowa, Iowa State University Press, 1995. 391p.

JOHNSON, C. B.; MANERING, J.V. \& MOLDENHAUER, W.C. Influence of surface roughness and clod size stability an soil and water losses. Soil Soc. Am. J.,43:772-777, 1979.

JULIEN, P.Y. Erosion and sedimentation. Melbourne, Cambridge University Press, 1995. 280p.

KOFFLER, N.F. \& LIMA, J.F.W.F. Caracterização edafoclimática das regiões canavieiras do Brasil: Pernambuco. Piracicaba, Divisão de Difusão de Tecnologia - IAA/ PLANALSUCAR, 1986. 78p.
KUHN, N.J. \& BRYAN, R.B. Drying, soil surface condition and interrill erosion on two Ontario soils. Catena, 57:113$133,2004$.

MERMUT, A.R.; LUK, S.H.; ROMHENS, M.J.M. \& POESEN, J.W.A. Soil loss by splash wash during rainfall from two loess soils. Geoderma, 75:203-214, 1997.

MEYER, L.D.; FOSTER, G.R. \& RÔMKENS, M.J.M. Source of soil eroded by water from upland slopes. In: Present and prospective technology for predicting sediment yields and sources. Washington, USDA, 1975. p.177-189.

MEYER, L.D. \& HARMON, W.C. Multiple intensity rainfall simulator for erosion research on row sideslopes. Trans. Am. Soc. Agron. Eng., 22:100-103, 1979.

PAIVA, E.M.C.D.; PAIVA, J.B.D.; MOREIRA, A.P.; MAFFINI, G.F.; MELLER, A. \& DILL, P.R.J. Evolução de processo erosivo acelerado em trecho do Arroio Vacacaí Mirim. R. Bras. Rec. Hídr., 6:129-135, 2001.

REICHERT, J.M.; SCHAFER, M.J.; ELTZ, F.L.F. \& NORTON, L.D. Erosão em sulcos e entressulcos em razão do formato de parcela em Argissolo Vermelho-Amarelo arênico. Pesq. Agropec. Bras., 36:965-973, 2001.

ROCKENBACH, C.A. Erosão em entressulcos sob diferentes coberturas por resíduos de trigo em um solo Podzólico Vermelho-Amarelo sob chuva simulada. Porto Alegre, Universidade Federal do Rio Grande do Sul, 1992. 108p. (Tese de Mestrado)

ROMKENS, M.J.M.; HELMING, K. \& PRASAD, S.N. Soil erosion under different rainfall intensities, surface roughness, and soil water regimes. Catena, 46:103-123, 2001.

SAS Institute. The SAS System for windows: Release ver. 6.8. Cary, 1998. CD-ROM

SIMONS, D.B. \& SENTURK, F. Sediment transport technology: water and sediment dynamics. In: Water resources publications. [Colorado], [s.ed.], 1992. 897p.

SINGH, V.P. Analytical solutions of kinematic for erosion on a plane: II Rainfall of finite duration. Adv. Water Res., 6:88-95, 1983.

WISCHMEIER, W.H. \& SMITH, D.D. Rainfall energy and its relationship to soil loss. Trans. Am. Geophys. Union, 39: 285-280, 1978.

WOOLHISER, D.A. \& LIGGETT, J.A. Unsteady onedimensional flow over a plane - the rising hydrograph. Water Res., 3:753-771, 1967.

ZARTL, A.S.; KLIK, A. \& HUANG, C. Soil detachment and transport processes from interrill and rill areas. Phys. Chem. Earth, 26: 25-26, 2001. 